\title{
DESARMAR LA CASA. Mudanza, cambio, pérdida.
}

\author{
Ángela Bonadies \\ angelabonadies@yahoo.com
}

Para Santi Pina, Maite Lertxundi y Laura Fernández, tres pérdidas cercanas. Y para María Matilde, Eli e Iris, a través de quienes los

conocí.

"Al perder nuestro hogar perdimos nuestra familiaridad con la vida cotidiana."

Hannah Arendt. Tiempos presentes

\section{$53^{\circ}$ Festival internacional de cine de San Sebastián. 15-24 de septiembre de 2005}

\section{Fuera y dentro del cine}

\begin{abstract}
Una cita sencilla, clara y dura abre este artículo que pretende hablar sobre la movilidad, el desmantelamiento de las razones y la mudanza como forma de construcción, como impulso -vital, mortal- para levantar un nuevo espacio plagado de ausencia. Arendt escribía en ese momento histórico que partió la moral del siglo XX y el carácter político y espiritual europeo: la segunda guerra mundial. Lo escribió en 1943 desde su exilio en los Estados Unidos y lo tituló "Nosotros, los refugiados". Aunque pensado desde un lugar muy específico, el artículo sirve como razón universal para hablar de cambios, pérdidas y mudanzas, del empaquetamiento de una vida anterior en pos de una venidera, no siempre buscada o deseada. En algunas ocasiones ese cambio no es una discontinuidad feliz sino una ruptura, un choque de frente con una situación impuesta, una amputación de perspectiva: oportunidad, novedad, azar, accidente, infortunio, pobreza, fractura, muerte. El inventario es amplio. El autor, como bien decía Serge Daney -a quien nunca me resulta repetitivo acudir- abre en perspectiva el círculo vicioso de la Historia o las historias y permite que sean narradas, dichas. El perímetro circular adquiere tres dimensiones y se convierte en esa ficción real que da volumen al mundo, que permite reconstruirlo en el tiempo como una esfera de recuerdos. "Al perder nuestro hogar perdimos nuestra familiaridad con la vida cotidiana. Al perder nuestra profesión perdimos nuestra confianza en ser de alguna manera útiles en este mundo. Al perder nuestra lengua perdimos la naturalidad de nuestras reacciones, la sencillez de nuestros gestos y la expresión espontánea de nuestros sentimientos. Dejar a nuestros parientes en los guetos polacos y a nuestros mejores amigos morir en los campos de concentración significó el hundimiento de nuestro mundo privado."
\end{abstract}


¿No es éste el sentimiento de los africanos que intentan llegar a Europa? Quizás lo que falta en este conflicto es que los autores de la narración reciban su "contrafirma", aquella que Derrida ha explicado en relación a la obra de arte, pero que puede extrapolarse: es necesario que exista una «comunidad» social que diga que esto ha sido hecho... No hay firma antes de la «contrafirma», que depende de la sociedad, las convenciones, las instituciones, del proceso de legitimación... Si no hay contrafirma, refrendo, la firma no existe. La firma no existe antes del refrendo. La ausencia de "nombres propios" del lado de África es quizás lo que facilita la ausencia de la contrafirma. La obsesión de Europa con la Europa Actual hace que se olvide el desierto social y político que dejó la Europea Colonial en África: un problema colectivo que llega a nuestros días y que hunde el mundo privado de millones de personas.

El hecho de miles de individuos atravesando el desierto del Sahara y su imagen de aquí para allá, en un intento por conseguir una especie de libertad, recuerda a una impresionante película de Peter Watkins -no proyectada en el festival- titulada Punishment Park (Estados Unidos, 1970) en la que como "juego institucional" se acusaba a una serie de jóvenes estadounidenses opuestos a la guerra de Vietnam (echando mano a la Ley de Seguridad Interna de 1950, la Ley MacCarran) de alteración del orden público y de representar un peligro para la seguridad interna de su país. Paso a citar un fragmento de la sinopsis realizada por el propio Watkins: el grupo 637 (formado sobre todo por estudiantes universitarios) se halla en el Parque Nacional de Castigo Bear Mountain, y descubre las reglas del "juego" que le obligan a seguir como parte de la alternativa que ha elegido, en lugar de la de ser confinado en una penitenciaría. Al Grupo 637 le han prometido la libertad si logra escapar a la persecución de los agentes de la ley y consigue llegar hasta una bandera estadounidense situada a 85 kilómetros a través de las montañas en el plazo de tres días... Deben llegar andando, sin agua, sin comida y con temperaturas extremas. En esta película, como bien apuntaba el historiador y profesor Scott MacDonald, se presentaba a un gobierno que pretendía con estos "parques de castigo" aleccionar y acabar con las oposiciones políticas y los movimientos de resistencia, por un lado, y por otro entrenar a los cuerpos de policía y de seguridad nacionales. Tildado de pesimista, histérico y paranoico, este cineasta inglés ha sido apreciado por algunos y pisoteado por muchos que lo consideran, como a sus propios personajes, un peligro ideológico radical.

La promesa de libertad en Punishment Park termina con el asesinato y linchamiento de los jóvenes y se convierte en un círculo vicioso: antes del Grupo 637 está el 636 y después el 638 y así sucesivamente: súbase la reja de defensa, auméntese el número de guardias y policías, depórtese. Como decía un poeta y citaba un escritor: el gusano está en el fruto.

\section{Desarmar el festival}

Alrededor del cambio, la pérdida y la mudanza se han estructurado buena parte de las películas proyectadas en esta $53^{\mathrm{a}}$ edición del festival de cine. Aunque por escenificar o mostrar el conflicto de "desarmar la casa" no todas hayan sido interesantes o consecuentes con la narración, en muchas se asoma la mudanza y el cambio como síntomas de un vacío económico, ideológico, social, afectivo; como necesidad y marca de nuestro tiempo. La pérdida es la causa y, en ocasiones, la consecuencia. En otras películas, demasiadas, el cambio y la mudanza se producen en el ritmo narrativo y juegan el confuso papel de estructura, por lo que la pérdida de sentido es la consecuencia. 
Buenos ejemplos de la temática de la mudanza y de la pérdida narrativa y estructural son dos de las películas que recibieron los principales premios del festival: Verano en Berlín (Sommer vorm balkon, Alemania) de Wolfgang Kohlhaase y Algo como la felicidad (Stesti, República Checa-Alemania) de Bohdan Sláma. Como muchas de las películas que estaban en competición en la Sección Oficial y en Zabaltegi (nuevas propuestas, perlas de otros festivales) éstas se perdían en la ambición de contar demasiadas cosas, incapaces de elaborar una idea y dentro de ella cavar y profundizar. Hablar de "una silla" o "esta silla" sin perder "la silla", hablar de una comunidad o una pareja sin dislocarse en mil pedazos melodramáticos o sin embadurnarse hasta las narices de problemas estallados, puntuales, superficiales. Dejar que la historia respire, que el círculo vicioso se abra. La narración es lo difícil. "El drama se padece, la tragedia se merece, como todo lo importante" apuntaba Lawrence Durrel en uno de los libros de su Cuarteto. Indudablemente en este festival padecimos en exceso.

De los premios da tedio hablar y es, creo, perder el tiempo. Siempre lo mismo: desubicados los del jurado eligen no se sabe con qué fórmula que la crítica es incapaz de comprender, a pesar de ser también esta última de diversa ralea. Si se busca información sobre el palmarés es mejor acudir a una hemeroteca y leer todos los periódicos del 25 de septiembre de 2005 para tener una idea cercana: nadie entendió nada. El artículo de Ángel S. Harguindey en El País es elocuente y me sumo a su opinión sobre una de las mejores películas de la Sección Oficial que no recibió nada de nada en un festival que da premios y premiecicos en exceso: A cock and bull story de Michael Winterbotton. Desarmados de presencia podría ser un buen título para una película sobre el jurado y sus decisiones.

Algo que se está convirtiendo en una rutina anual funcionó de nuevo, y es normal: las películas programadas dentro de los ciclos especiales superaron en calidad a casi todas las que desfilaron por la Sección Oficial y Zabaltegi, es decir, las novedades no son ni muy buenas ni muy nuevas. En particular disfruté de algunas películas proyectadas en el ciclo "Rebeldes e insumisas", films de todos los tiempos sobre mujeres fuertes o simplemente decididas. Esta sección salvó algunos días del festival que se tornaron nefastos, aunque también es importante decir que el estado de la mayoría de las películas de esta sección era lamentable, que los subtítulos brillaban por su ausencia por largos espacios de tiempo o no estaban sincronizados con el sonido y que, por qué no echar más leña al fuego, la selección fue irregular, probablemente por lo amplio del enunciado. Algunas brillaron, eso sí: La Reina Cristina de Suecia de Rouben Mamoulian; La vieja dama indigna de René Allio; Siete mujeres de John Ford; Messidor de Alain Tanner; Gloria de John Cassavetes; Encuentro de dos reinas de Cecilia Barriga.

El otro gran ciclo fue una retrospectiva dedicada al director Robert Wise, maestro en diversos géneros que murió el día antes de arrancar el festival.

\section{De fosa en fosa: cambio de ritmo, pérdida de sentido}

Odgrobadogroba (De fosa en fosa) de Jan Cvitkovic, Eslovenia, 2005

Es esta una excepción que me permito: escribir sobre De fosa en fosa, película de la Sección Oficial que recibió el premio Altadis - Nuevos Directores. Lo hago porque me parece una muestra sintomática del mal que sufren buena parte de las películas proyectadas, entre ellas las arriba nombradas Stesti y Sommer vorm Balkon, aunque Odgrobadogroba es la que considero más interesante y en la que me decepcionó más la pérdida de sentido. 
De fosa en fosa comienza con un movimiento circular que se centra en un orador funerario, en su familia y sus amigos: un abuelo suicida que ha perdido el deseo y lo recupera; una hermana con problemas matrimoniales, su esposo y su hijo; un amigo incondicional, su coche, su relación con otra hermana del orador -sorda-, una vecina de la que se enamora el orador y el padre de ella. Por un buen rato todo bien, pero el círculo que va describiendo las relaciones pierde abruptamente su centro en la parte final por un cambio de registro, de ritmo, de género, y pasa de una bien lograda "triste alegría" a una especie de carrera a ninguna parte. A diferencia de Stesti y Sommer vorm Balkon, que se dislocan rápidamente y se dispersan en varios melodramas, De fosa en fosa se desarticula en una última parte de no sé exactamente cuántos minutos. Más que arriesgada la decisión, si lo fue, me pareció inadecuada, tediosa, aburridamente violenta, puesto que no había un previo narrativo que la justificara. Si bien dentro de la película un "hecho" justificaba en cierta medida el cambio, no era suficiente para establecer una continuidad honesta con el espectador.

Sumergida en un ambiente entre festivo, depresivo y mágico, los personajes van adquiriendo gradualmente familiaridad, hasta que en la citada "parte final" uno de los más sugerentes y delicados se transforma de un golpe, apelando -el director- a la discontinuidad, sin respetar argumentos que lo sustenten. ¿Cómo explicarlo? Existen buenos ejemplos de transformaciones o transmutaciones en el cine. En Tiempo de gitanos de Emir Kusturica el joven deviene matón y vividor por circunstancia, por evolución, como el hombre de El Dinero (L'Argent, 1983) de Robert Bresson o las dos muchachas de Messidor de Alain Tanner (Francia-Suiza, 1979, proyectada en el ciclo Rebeldes e Insumisas del festival).

Evolución de los "modelos" -para usar un término del propio Bresson- es lo que hay en estas tres películas, no "reacción" de los personajes, como en De fosa en fosa, que sólo nos tiende una trampa efectista. El espectador es sometido a un viaje injusto: de atmósferas evocadoras de suaves matices irónicos, compuestos y complejos, a un clima de tosca confusión y griterío. Lo peor es que, probablemente, fue para justificar un final de titular algo televisivo. Lástima.

\section{Gloria: Perder la casa}

Gloria de John Cassavetes, Estados Unidos, 1980

Desde el primer segundo comienza Gloria, la original, la de Cassavetes. Despega con tomas en helicóptero de la ciudad de Nueva York, con paisajes que prefiguran las fotografías de Andreas Gursky: autopistas abarrotadas, grandes edificios de oficinas, el público en el estadium, los puentes transitados, mucha gente y nadie reconocible, como las fotos del alemán. Cassavetes nos sitúa así en esa "tierra de nadie y de todos" para luego hacernos aterrizar en plena calle, dentro de un autobús, en el viaje de una mujer con miedo de la que no sabemos nada, salvo que tiene miedo. Nos hace seguirla hasta su edificio, vigilado por gente de la que tampoco sabemos nada, salvo que por sus trajes y caras no son amigables. Cuando entramos a su casa, a la de la mujer, conocemos a su familia boricua-niuyorquina, que la espera. Esposo, una hija, un hijo y su madre. El esposo está tan asustado como ella ¿Viste a alguien al entrar? ¿Hombres? ¿Cómo iban vestidos? La última pregunta nos responde: la mafia. Él era contable de la mafia y dio nombres, vendió información y se puso en evidencia. Ellos no perdonan y eso se sabe. Conocemos a la familia en un momento de crisis: saben que van a morir. En plena angustia tocan la puerta y es Gloria, vecina y amiga de la mujer, a quien le piden que salve a sus dos hijos. Gloria no quiere: odia a los niños, vive tranquila, sola, sola con su 
gato que desaparece en la primera secuencia de escape. La hija no va, se queda con sus padres, el hijo se va con Gloria y se le confía el cuaderno de contable, con nombres y números de la mafia. Gloria y Phil, el niño, escuchan la masacre. Han pasado pocos minutos desde el comienzo: la película arranca con violencia y ese será el contexto permanente de los dos personajes que van desde el rechazo hasta el amor. También en círculos viciosos se despliega el espacio en el tiempo de Gloria y Phil, que se separan y se juntan, se empujan, se mueven de prisa entre calles, moteles y apartamentos clandestinos. Gloria conoce a la gente que mató a su familia, son mis amigos -dice. Sin embargo, rápidamente muestra su pistola y acaba con parte de esos amigos en una de las secuencias emblemáticas de la película, de donde se extrajo el fotograma que la identifica. Desde ese momento ella es tan perseguida como Phil y, en igualdad de condiciones, sólo se tienen el uno al otro, de modo que fundan una nueva familia: "You're my mother, you're my father, you're my whole family. You're even my friend, Gloria. You're my girlfriend, too" -dice Phil. Y así es, así actúan, como una verdadera familia con sus matices y contradicciones: dando la espalda, salvando, hablando, peleando, empujándose, en silencio, poniendo claras las cosas, arriesgando, perdiendo. Esta es una historia de amor que se desarrolla entre la pérdida y la mudanza, en un terreno peligroso, en un campo minado. Ahí aterriza la película de Cassavetes, este es su movimiento: desde la ciudad sobrevolada, pasando a ras de tierra por sus calles y gente, hasta afincarse en el sentimiento, clavarse en lo más profundo de sus personajes, que se niegan a perderlo todo en lo que parece, pero no es, un único y agotador día. Gloria enseña a Phil a despedirse de sus muertos, en un cementerio cualquiera, y así hacer el duelo que le permita construir otra casa, mudarse. Le ofrece la posibilidad de articular la pérdida y la vida, la separación.

El final es la culminación de ese amor que se disfraza para ser multiforme y reparar, en la medida de lo posible, lo irreparable. Merecido final feliz.

\section{Me and you and everyone we know: dividir la casa}

Me and you and everyone we know (Tú, yo y todos los demás) de Miranda July, Estados Unidos, 2005. Proyectada en el festival en la Sección Zabaltegi de Joyas de otros festivales.

Dividir parece ser el término que define a esta película. Dividir y su contraparte, unir lo dividido, lanzar puentes entre "una cosa" y "otra cosa", entre "yo" y "tú" y "cada uno de los que conocemos". También entre "video creación" y "cine", entre vejez, niñez y adultez, juntarlos sin que cada uno pierda su lenguaje, sin prejuicio ni perjuicio, sin dominantes. Y eso es raro y más raro aún cuando está logrado y conmueve.

El término "yo" de la película nombra a una artista visual interpretada por la propia Miranda July, directora y actriz que es también artista visual. "Yo", la artista o creadora, no está representada a la manera convencional en que hemos visto desfilar a pintores, escultores y escritores en el cine, con una mezcla empalagosa de apología, mito, excentricidad y depresión donde la tendencia es a construir panegíricos y estatuas de celuloide. En esta película no ocurre nada de eso, al contrario. Miranda July habla de la creación contemporánea desde adentro, desde su producción casera e íntima con humor y ternura, desde la experiencia de quien vive para el arte y establece una relación artística con el mundo, no cargada de trascendencia rancia (me refiero de nuevo a esas películas que convierten al artista en una caricatura culto-excéntrica) sino de una banalidad trascendental en la que el círculo abarcador no va "del cielo a la tierra" sino es envolvente y se mueve a la altura de los ojos, 
del corazón, de los coches, del sexo, de todos: a la altura de "yo, tú y cada uno de los que conocemos". Me refiero a esa banalidad que trasciende de la que hablan artistas como Gabriel Orozco, en la que el hombre y su escala ocupan un espacio real y lo marcan, se apoyan, lo ocupan, lo besan, lo descubren.

Dentro de esa envolvente división y unión funcionan los personajes de la película, que comienza con la escena de una pareja separándose. Él, el hombre que se separa de la mujer con la que tiene dos hijos, será el "tú" que nombra el segundo término del film. Él (tú) tiene la responsabilidad de montar otra casa para sus hijos y no es poca cosa: quiere hacerlo bien y que sea diferente. Un hijo adolescente, un segundo hijo más pequeño, una ex-esposa, un hombre mayor para quien ella (yo) conduce y una mujer mayor que es su novia, una comisaria de exposiciones, dos muchachas adolescentes, un compañero de trabajo de él (tú) y una pequeña vecina y su madre completan el espacio que cierra el título: "everyone we know", cada uno de los que conocemos, que va del singular del individuo al plural de la pareja y cada uno de los suyos, sin confundirlos. Por esa razón no me pareció apropiado el título en español que se le dio en el festival: Tú, yo y todos los demás. No, no son los demás ni los otros, son importantes, tan importantes que son el tercer término del título. Son "aquellos que están cerca", no un simple decorado contextual o anecdótico. Son, junto con "yo" y "tú", la película.

Miranda July también nos habla del misterio (por qué no: del arte) como algo real, banal, cercano, que no todos perciben. Nos habla del misterio y el milagro de descubrirlo sin restarle emoción. En particular algunas escenas de la película lo revelan: la mano quemándose (al principio); la niña y su ajuar de novia; el encuentro en el parque (misterio que no voy a revelar); la moneda que golpea un tubo en la calle (al final). Misterios y milagros cotidianos que plagan el relato a escala humana.

Las referencias de July a la revisionista, bizarra y posmoderna cultura contemporánea son variadas: La Cenicienta ("tú" es vendedor de zapatos y así lo conoce "yo"), la cibercultura, el sexo, los grandes conciertos (en uno de sus videos), la muerte (otro video), el cine (fotografías narradas a la manera de los trabajos más experimentales de Wenders), el mundo del arte, el sonido, la música, el trabajo y las fantasías.

Por último: el dibujo que el hijo menor de "tú" hace para su escatológica amante virtual representa con mucho sentido del humor el puente que une y divide y la altura de la narración: anal, sexual, orgánica, ventricular, circular; reinterpretada como anagrama y estatus del mejor arte contemporáneo.

\section{Los Olvidados: la casa fuera}

\section{Los Olvidados de Luis Buñuel, México, 1950}

En boca de un escritor escuché hace poco una cita de Las Mil y una noches: "El mundo es la casa de los que no la tienen". Con el efecto vicioso y circular que viene conduciendo el artículo unimos esta cita con las palabras iniciales de Arendt: "Al perder nuestro hogar perdimos nuestra familiaridad con la vida cotidiana." Útil y justo para comenzar y terminar de hablar de-con esta película de Buñuel, proyectada en una sesión especial del ciclo Horizontes Latinos del festival de San Sebastián.

Unidas, encadenadas, ambas citas componen el espacio desestructurado y roto de "la casa" en el que se mueven los niños y adolescentes de Los Olvidados. Ellos hacen de las calles sus pasillos y la vida cotidiana es un completo azar, un descubrimiento diario, una nueva emboscada de ellos o contra 
ellos. No hay futuro más joven que el de estos muchachos, ni familiaridad más extraña. Manchas impregnadas del sucio de la calle en la vigilia y el sueño, la marca en el cuerpo y las fantasías, en el delirio. La marca de Luis Buñuel en sus películas, ese frote de quien reconoció: "Los Olvidados es para mí efectivamente un filme de lucha social. Porque creo ser sencillamente honesto conmigo mismo, debía hacer una obra de tipo social. Yo sé que voy en esa dirección. Aparte de eso, no he querido hacer un filme de tesis. Había observado cosas que me habían emocionado y quise trasponerlas a la pantalla, pero siempre con esa especie de amor que siento por lo instintivo y lo irracional que puede aparecer en todo. Siempre me he sentido atraído por el lado desconocido o extraño que me fascina sin saber por qué."

\section{Referencias}

Arendt, Hannah. Tiempos presentes. Gedisa Editorial, Barcelona, 2002. Traducción de R. S. Carbó.

Daney, Serge. Cine, arte del presente. Santiago Arcos editor, Buenos Aires, 2004. Antología al cuidado de Emilio Bernini y Domin Choi.

Derrida, Jaques. "Las artes espaciales". Una entrevista con Jacques Derrida por Peter Brunette y David Wills en Acción Paralela: http://www.accpar.org/numero1/derrida1.htm

Gabriel Orozco en Villa Iris. Fundación Marcelino Botín, Santander, 2005.

Harguindey, Ángel S. "El filme checo Stesti logra la Concha de Oro". En el diario El País, domingo 25 de septiembre de 2005.

Renoir, Jean y otros. La política de los autores. Colección: La memoria del cine 17. Ediciones Paidós, Barcelona, 2003. Traducción de Miguel Rubio.

Tanizaki. Elogio de la sombra. Ediciones Siruela, 1995, Madrid. Traducción de Julia Escobar.

Watkins, Peter. Historia de una resistencia. Edita: E.M.A.M. Teatro Municipal Jovellanos de Gijón y Festival Internacional de Cine de Gijón, 2004. Edición y prólogo: Ángel Quintana. Traducción: Juan José Pulido.

\section{Formato de citación}

Bonadies, Ángela (2005). Desarmar la casa. Mudanza, cambio, pérdida. Athenea Digital, 8. Disponible en http://antalya.uab.es/athenea/num8/bonadies.pdf 


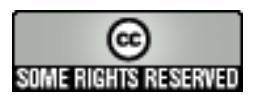

Este texto está protegido por una licencia Creative Commons.

Usted es libre de copiar, distribuir y comunicar públicamente la obra bajo las siguientes condiciones:

Reconocimiento: Debe reconocer y citar al autor original.

No comercial. No puede utilizar esta obra para fines comerciales.

Sin obras derivadas. No se puede alterar, transformar, o generar una obra derivada a partir de esta obra.

\section{$\underline{\text { Resumen de licencia }}$}

$\underline{\text { Texto completo de la licencia }}$ 